OPEN ACCESS

Edited by:

Silvia Gabrielli,

Bruno Kessler Foundation (FBK), Italy

Reviewed by:

Rubina Hanif,

Quaid-i-Azam University, Pakistan

Elke Struyf,

University of Antwerp, Belgium

${ }^{*}$ Correspondence: Henk Weymeis

henk.weymeis@ugent.be

Specialty section:

This article was submitted to Psychology for Clinical Settings,

a section of the journal

Frontiers in Psychology

Received: 03 July 2020 Accepted: 24 March 2021

Published: 27 April 2021

Citation:

Weymeis $\mathrm{H}$, Van Leeuwen $\mathrm{K}$ and

Braet C (2021) The Effects of

TIME-IN on Emotion Regulation,

Externalizing, and Internalizing

Problems in Promoting

School Readiness.

Front. Psychol. 12:579810.

doi: 10.3389/fpsyg.2021.579810

\section{The Effects of TIME-IN on Emotion Regulation, Externalizing, and Internalizing Problems in Promoting School Readiness}

\author{
Henk Weymeis ${ }^{1 *}$, Karla Van Leeuwen ${ }^{2}$ and Caroline Braet ${ }^{1}$ \\ 'Department of Developmental, Personality, and Social Psychology, Ghent University, Ghent, Belgium, ${ }^{2}$ Parenting and \\ Special Education Research Unit, KU Leuven, Leuven, Belgium
}

Children's readiness for school is often threatened by the occurrence of both externalizing and internalizing problems. Previous research has shown that Positive Behavioral Interventions and Supports (PBIS) is particularly effective for fostering children's behavioral skills and reducing externalizing problems. However, whether PBIS can enhance children's emotional skills and reduce internalizing problems is less clear. Therefore, TIME-IN was developed, which extends PBIS by also including emotional support systems. It was tested whether TIME-IN was effective for (a) improving emotion regulation and (b) reducing depressive symptoms. Furthermore, it was tentatively explored whether TIME-IN is accompanied by more than natural fluctuations in both children's externalizing and internalizing problems. The effectiveness of TIME-IN was evaluated in a non-randomized study, in which an intervention group was compared with a matched control group. Both research questions were addressed in a sample consisting of 81 children between 8 and 12 years of age with special educational needs. Questionnaires for teachers (i.e., TRF), children (i.e., FEEL-KJ and CDI), and their parents (i.e., CBCL) were administered at the beginning (TO) and the end of the school year (T1) using multi-informant assessment. Only indicative evidence was found for the hypothesis that TIME-IN improved children's emotion regulation. Practical implications, strengths, and limitations were discussed.

Clinical Trial Registration: This work was retrospectively registered at International Standard Registered Clinical/soCial sTudy Number (ISRCTN) registry ISRCTN54456609 (Weymeis, 2017). Registered 28 March 2017.

Keywords: externalizing problems, internalizing problems, emotion regulation strategies, school readiness, school-wide health care policy

\section{INTRODUCTION}

\section{Enhancing School Readiness of Children With Special Educational Needs}

In a review of the UNICEF (Britto, 2012), school readiness has been broadly conceptualized as successfully adapting to the school environment, which is facilitated by gaining specific competencies (i.e., skills, abilities, and attitudes). In this regard, the current study specifically focused on the behavioral and emotional dimensions of school readiness (see, e.g., Blair and Raver, 2015). 
With regard to promoting school readiness, UNICEF recommended paying particular attention to young, vulnerable, and/or disadvantaged children with special educational needs. Special educational needs (SEN) has been defined as "learning difficulties or disabilities that make it harder for them to learn or access education than most children of the same age. These children may need extra or different help from that given to other children of the same age" (Westwood, 2007, p. 1).

In Flemish education with a current rate of $60.09 \%$, the largest group of children with SEN is children with learning problems and/or a mild intellectual disability (Flemish Government, 2017). Some of these children receive schooling in regular education, while other more vulnerable children receive special education which can be referred to as "type basisaanbod" education (i.e., cross-national categories A and B; Organisation for Economic Co-operation and Development, 2005; Flemish Government, 2014). Type basisaanbod includes young people with SEN for whom the common curriculum with reasonable adjustments is (temporarily) not feasible in a school for regular education (see, e.g., Farran and Shonkoff, 2010). Because of their specific needs, emotional and behavioral difficulties can also be related to these problems (Dekker et al., 2002; Morgan et al., 2008), in which cause and effect are still difficult to determine. Consequently, the school system (i.e., both regular and special education) in the Flemish part of Belgium is burdened by the load of SEN, concentrated in special education schools. In the current study, specific attention is given to children with learning problems and/or a mild intellectual disability in special education.

Special educational needs children's emotional and behavioral problems are typically reflected in two well-known variables: externalizing (EP) and internalizing (IP) problems (see, e.g., Baker et al., 2008). EP have been defined as "overt, disruptive behaviors that often involve the violation of societal norms, the destruction of property, and harm towards others" (Keil and Price, 2006, p. 763), whereas IP have been conceptualized as "problems related to anxiety, fear, shyness, low self-esteem, sadness, and depression" (Ollendick and King, 1994, p. 918). Specific attention is needed for this at-risk group given the EP and IP impeding their further school career and possible long-term reintegration into mainstream education. In this regard, research already demonstrated the direct impact of Positive Behavioral Interventions and Supports (PBIS) and its well-known cognitive-behavioral interventions on SEN children's EP (Cheney et al., 2008; Lane et al., 2008; Horner et al., 2009; Wills et al., 2010), as well as its possible indirect impact on IP (Hunter et al., 2013). However, given the fact that EP and IP have been shown to be highly comorbid (Wolff and Ollendick, 2006), and IP are often underserved, it has been stated by McIntosh et al. (2014) that PBIS policy developers should also deliberately incorporate emotional learning interventions that have been assumed to have direct impact on IP. Emotional learning interventions that seem to meet this criterion are those that are specifically intended for improving children's emotion regulation (ER), which has been (a) defined by Gross (1998, p. 224) as "processes by which individuals influence which emotions they have, when they have them, and how they experience and express these emotions," and (b) shown to be a transdiagnostic mechanism that affects both EP and IP (Aldao et al., 2016). Improving emotion regulation is more specifically reflected in acquiring adaptive emotion regulation strategies to the detriment of maladaptive emotion regulation strategies. Important adaptive ER strategies are emotional awareness, identifying emotions, understanding emotions, modifying negative emotions (e.g., through cognitive reappraisal or problem solving), and accepting negative emotions (Aldao et al., 2010; Berking and Lukas, 2015). Well-known maladaptive ER strategies are avoidance, rumination, and suppression (Aldao et al., 2010). Moreover, emotional learning interventions might have the potential to positively affect children with learning problems and/or mild intellectual disability (Bauminger and Kimhi-Kind, 2008; Mcclure, et al., 2009). Interestingly, the adjustments proposed by McIntosh et al. (2014) are in line with the growing tendency to combine PBIS with social and/ or emotional learning programs (SEL; see, e.g., Osher et al., 2010; Bradshaw et al., 2014; Cook et al., 2015); however, (a) the integrated version has hardly been investigated so far and (b) to date, very few SEL programs exclusively focus on children's emotional learning (Rimm-Kaufman and Hulleman, 2016).

To fill this gap, a school-wide health care policy has been developed, named TIME-IN (Weymeis, 2015). ${ }^{1}$ TIME-IN aims to extend PBIS with emotional learning interventions such as (a) screening instruments for identifying IP, (b) emotion regulation training, and (c) crisis intervention strategies. It has been considered useful to train children's adaptive ER strategies by means of the key principles of Affect Regulation Training (ART; Berking and Schwarz, 2014), which has several advantages since ART integrates different adaptive ER strategies into one coherent model and is effective for reducing various mental health problems (Berking and Lukas, 2015). Currently, ART has only been evaluated in adults and young adolescents (Volkaert et al., 2018), although it was claimed that ART is also applicable to younger age groups (Berking and Schwarz, 2014). Furthermore, to support emotionally overwhelmed children, Life Space Crisis Intervention (LSCI; Long et al., 2003) was used, which was stated to fit well within a schoolwide approach (Dawson, 2003), and was found to be effective for children with SEN (Soenen et al., 2014). For a more in-depth description of TIME-IN, including study design and CONSORT diagram (see also Figure 1), visualized continuum of PBIS, program description, and program delivery, see the recently published study protocol (Weymeis et al., 2019b). ${ }^{2}$ The current study will mainly address the question whether TIME-IN is effective for (a) enhancing adaptive ER to the detriment of maladaptive ER and (b) reducing both EP and IP in children with SEN.

\section{The Current Study: Evaluating TIME-IN}

TIME-IN was implemented in a real-life setting (i.e., special education). In the current study, a practice-based evaluation

${ }^{1}$ https://www.acco.be/nl-be/items/9789462922884/Wij-zijn-gedrag

${ }^{2}$ http://journals.ed.ac.uk/social-science-protocols/article/view/3038 (public access). 


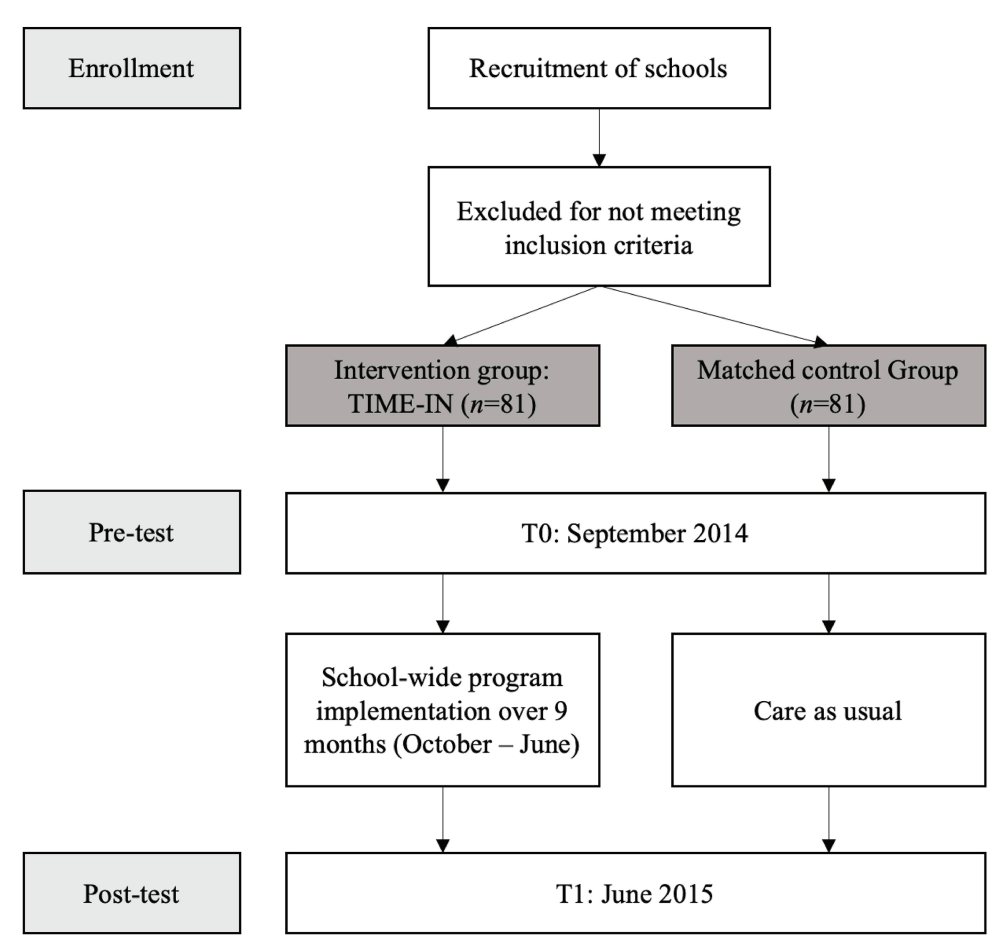

FIGURE 1 | TIME-IN study design. Study progress from enrollment, pre-test to post-test.

was used to determine whether or not TIME-IN is potentially effective for promoting children's school readiness (Veerman and van Yperen, 2007; Simons et al., 2016). For an overview of related criteria and considerations, see Weymeis et al. (2019b).

The first goal of the current study was to investigate whether TIME-IN is effective for improving child-reported emotion regulation and decreasing both EP and IP. More specifically, the confirmatory hypotheses were tested that, in the intervention group, TIME-IN was beneficial for enhancing adaptive ER strategies, reducing maladaptive ER strategies, and lowering depressive symptoms. In contrast, it was expected that no such changes would occur in the control group. Furthermore, the second goal of the current study was to tentatively explore whether TIME-IN is also accompanied by reductions in both parent- or teacher reported EP and IP. To deduce whether any reductions in EP and IP are due to the impact of TIME-IN, we controlled for natural fluctuations, related to children's regular development during this age period (e.g., see Bronfenbrenner, 1977) in a matched control group.

\section{MATERIALS AND METHODS}

\section{Participants}

The current study was conducted in the Flemish part of Belgium. Participants for both the intervention and control group were recruited using opportunity sampling. One Flemish elementary school providing special education for children between 6 and 12 years of age with SEN was selected by the government as an intervention group. However, it has been stated that well-designed clinical trials consisting of small sample sizes may yield substantial evidence as long as the results are approached in a critical manner (Institute of Medicine, 2001). Participants in the intervention group were 81 Caucasian children between 8 and 12 years of age with $\operatorname{SEN}\left(M_{\text {age }}=10.27, S D=1.36,63 \%\right.$ boys $)$, as well as their teachers and parents. Unfortunately, insufficient funds were available to prospectively include a control group in the current research project. Therefore, given the opportunity, the control group was retrospectively selected from the concurrent Generation 2020 study (see Van Beveren et al., 2016), which focused on screening children's school readiness, but did not provide any interventions. More specifically, 11 elementary schools providing regular education for children between 8 and 12 years were included in the study to select the control group. Eighty-one Caucasian children (51 males, mean age $=10.27, S D=1.36$ ), as well as their parents, were randomly recruited from these 11 schools using SPSS casecontrol matching for age and gender. A full description of the sample is provided in Table 1.

Regarding the intervention group, children, parents, and teachers who did not give their explicit consent to participate were removed from the study. Furthermore, all children whose age did not correspond to the norm group of the primary measures (6-8 years old; see assessments and measures section) or had a different SEN status (i.e., children with a severe mental health and/or physical disability) were excluded from the study at the time of admission. To be able to accurately identify the capacities of children with learning problems (i.e., IQ score > 70) and/or a mild intellectual disability (i.e., IQ score $\geq 55$ and $\leq 70$; American Psychiatric Association, 2013), 
TABLE 1 | Sample table for describing participants.

\begin{tabular}{|c|c|c|}
\hline Descriptive variables & Intervention group & Control group \\
\hline \multicolumn{3}{|l|}{ Gender } \\
\hline $\begin{array}{l}\text { Male } \\
\text { Female } \\
\text { Total }\end{array}$ & $\begin{array}{c}n=51(63.0 \%) \\
n=30(37.0 \%) \\
81\end{array}$ & $\begin{array}{c}n=51(63.0 \%) \\
n=30(37.0 \%) \\
81\end{array}$ \\
\hline \multicolumn{3}{|l|}{ Age } \\
\hline $\begin{array}{l}\text { Mean } \\
\text { Range } \\
\text { Race/ethnicity }\end{array}$ & $\begin{array}{c}10.27 \\
4.0(8.0-12.0) \\
\text { Caucasian }\end{array}$ & $\begin{array}{c}10.27 \\
4.0(8.0-12.0) \\
\text { Caucasian }\end{array}$ \\
\hline \multicolumn{3}{|l|}{ Socioeconomic status } \\
\hline $\begin{array}{l}\text { Upper class } \\
\text { Upper-middle class } \\
\text { Middle class } \\
\text { Lower-middle class } \\
\text { Lower class }\end{array}$ & $\begin{array}{r}0.00 \% \\
17.30 \% \\
53.10 \% \\
23.50 \% \\
6.20 \%\end{array}$ & $\begin{array}{r}1.20 \% \\
43.20 \% \\
48.10 \% \\
7.40 \% \\
0.00 \%\end{array}$ \\
\hline \multicolumn{3}{|l|}{ Intelligence } \\
\hline $\begin{array}{l}\text { IQ score } \leq 70 \\
\text { IQ score }>70 \\
\text { Time frame data } \\
\text { collection }\end{array}$ & $\begin{array}{c}n=27(33.30 \%) \\
n=54(66.70 \%) \\
2005-2014\end{array}$ & IQ scores not available \\
\hline $\begin{array}{l}\text { Mean } \\
\text { Range }\end{array}$ & $\begin{array}{c}75.61 \\
55-110\end{array}$ & $>90$ \\
\hline Geographical location & Urban & Urban \\
\hline
\end{tabular}

"Names of tests used: SON-R, WISC-III, and WPPSI-R.

full scale intelligence scores were provided by the school (i.e., secondary data) and derived from three different intelligence tests (Dutch versions): the Snijders-Oomen Non-Verbal Intelligence test-R (SON-R; Laros et al., 1991), the Wechsler Intelligence Scale for Children-III (WISC-III; Kort et al., 2002), and the Wechsler Preschool and Primary Scale of Intelligence-R (WPPSSI-R; Vander Steene and Bos, 1997). These tests were equally standardized (mean $=100.0, S D=15.0$ ) and, moreover, were found to be strongly interrelated (Tellegen et al., 1998). Little's MCAR test showed no evidence that the data were not missing completely at random for all study variables in the intervention group, $\chi^{2}(58, N=81)=62.95, p=0.31$ (EXT/ INT T0: $2.50 \%$; EXT/INT T1: 24.70\%; Adaptive/Maladaptive ER T0: $13.60 \%$; Adaptive/Maladaptive ER T1: 11.10\%; and CDI T0/T1: 3.70\%; Little, 1988). Therefore, missing values were imputed using SPSS expectation maximization (EM). The distribution of scores on the study variables in the normal, subclinical, or clinical range are presented in Table 2 .

With regard to the control group, a full description of the sample is provided in Table 1. Compared to the intervention group, socio-economic status seemed to be differently distributed, $\chi^{2}(4, N=162)=21.96, p<0.001$ in the control group, which included less lower-middle class and more upper-middle class families. Next, IQ scores were not available for the control group, but placement in regular education assumes IQ scores within the normal range (i.e., IQ score $\geq 90$; Voeller and Heilman, 1988; Kaufman et al., 2016). Finally, Little's MCAR test showed that missing data in the control group was missing completely at random, $\chi^{2}(25, N=81)=31.32, p=0.18$ (EXT/INT T0: 2.50\%; EXT/INT T1: 45.7\%; Adaptive/Maladaptive ER T0: $1.20 \%$; Adaptive/Maladaptive ER T1: 43.20\%; CDI T0:
0.0\%; and CDI T1: 43.20\%). Therefore, missing values were imputed here also using SPSS expectation maximization (EM). The distribution of scores on the study variables in the normal, subclinical, or clinical range are presented in Table 2 .

\section{Procedure}

The current study was approved by the ethical committee of Ghent University. Teachers, children, and their parents received a letter consisting of an explanation of the aims and procedures of the study, an invitation to participate, as well as a request to give consent to provide demographics and fill in relevant outcome measures. Consequently, children, parents, and teachers were requested to sign the informed consent form (IC). Also, a short presentation was held in the intervention group to inform parents and teachers about the content of TIME-IN and the related research. Consequently, access was provided to an online tool in order to be able to complete questionnaires at T0 and T1. Children were asked to complete questionnaires on ER and depressive symptoms in both the intervention and the control group. In the intervention group, SEN children received verbal support by repeating items out loud, or by explaining the items in a standardized way using concrete examples. Furthermore, caregivers were requested to complete questionnaires at home or in the classroom. More specifically, teachers were asked to fill out a questionnaire on children's EP and IP in the intervention group, whereas parents were requested to complete a comparable questionnaire in the control group. The overall data collection was conducted by one additional researcher of Ghent University.

\section{Assessments and Measures Primary Outcomes \\ Adaptive and Maladaptive ER Strategies: FEEL-KJ}

The 90-item Fragebogen zur Erhebung der Emotionsregulation bei Kindern und Jugendlichen was used (FEEL-KJ; Grob and Smolenski, 2005), Dutch version by Braet et al. (2013), to measure a broad range of ER strategies in children and adolescents between 8 and 18 years old. More specifically, the FEEL-KJ assesses different emotion regulation strategies in children's response to anxiety, sadness, and anger. It obtains two total scores. First, total Adaptive emotion regulation strategies are measured by calculating the scores of seven different strategies: Cognitive Problem-Solving, Problem-Solving, Acceptance, Forgetting, Distraction, Revaluation, and Evoking Positive Mood. Second, total Maladaptive emotion regulation strategies are measured by calculating the scores of five different strategies: Giving Up, Withdrawal, Aggression, Self-Devaluation, and Rumination. Each strategy is measured by rating two items for each of the three emotions, whereby answers are given on a 5-point Likert scale. The FEEL-KJ has been shown to be wellvalidated and reliable (see Table 3; Cracco et al., 2015).

\section{Depressive Symptoms: CDI}

The Children's Depression Inventory (CDI; Kovacs, 1992), Dutch version by Timbremont and Braet (2002), is a 27 -item selfreport questionnaire for assessing cognitive, affective, and 
TABLE 2 | The number ( $n=$ ) of children in the normal, subclinical, or clinical range at T0 and T1.

\begin{tabular}{|c|c|c|c|c|c|c|}
\hline \multirow{2}{*}{$\begin{array}{l}\text { Conditions } \\
\text { Intervention group }\end{array}$} & \multicolumn{3}{|c|}{ T0 = Baseline } & \multicolumn{3}{|c|}{ T1 = 9 months later } \\
\hline & Normal & Subclinical & Clinical & Normal & Subclinical & Clinical \\
\hline 1. Adaptive ER & 72 & 8 & 1 & 71 & 6 & 4 \\
\hline 2. Maladaptive ER & 62 & 9 & 10 & 65 & 14 & 2 \\
\hline 3. Depressive symptoms & 44 & 25 & 12 & 51 & 17 & 13 \\
\hline 4. EXT & 59 & 11 & 11 & 64 & 11 & 6 \\
\hline 5. INT & 58 & 8 & 15 & 66 & 12 & 3 \\
\hline Control group & Normal & Subclinical & Clinical & Normal & Subclinical & Clinical \\
\hline 1. Adaptive ER & 71 & 10 & 0 & 77 & 3 & 1 \\
\hline 2. Maladaptive ER & 70 & 10 & 1 & 74 & 6 & 1 \\
\hline 3. Depressive symptoms & 66 & 11 & 4 & 64 & 11 & 6 \\
\hline 4. EXT & 70 & 9 & 2 & 73 & 6 & 2 \\
\hline 5. INT & 64 & 10 & 7 & 72 & 7 & 2 \\
\hline
\end{tabular}

EXT, externalizing; INT, internalizing; ER, emotion regulation.

behavioral symptoms of depression in children and adolescents between 7 and 17 years of age. Answers for each item are given on a 3-point Likert scale indicating level of severity. The CDI has been shown to be well-validated and reliable (see Table 3; Smucker et al., 1986; Craighead et al., 1998).

\section{Secondary Outcomes}

Externalizing and Internalizing Problems: TRF and CBCL

The Teacher Report Form (TRF; intervention group) and Child Behavior Checklist (CBCL; control group; Achenbach and Rescorla, 2001), Dutch versions by Verhulst et al. (1996, 1997), respectively, are 113-item questionnaires for measuring teachers' and parent's perceptions of 6- to 18-year-old children's adaptive and maladaptive functioning. The TRF and CBCL are wellvalidated and reliable (see Table 3; Achenbach et al., 2003). In the intervention study, children's teachers reported on EP and IP, whereas in the control group, parents were informants of children's EP and IP. Comparing parents' and teachers' reports on these measures seems reasonable, as previous research showed modest cross-informant agreement between parents and teachers regarding children's EP and IP (Achenbach et al., 2002). However, this is only for descriptive purposes as we are primarily interested in the (experimentally manipulated or naturally) fluctuations between the scores during the 9-month project, thereby comparing pre-test vs. post-test scores of the same informant.

\section{Data Analytic Plan}

Firstly, descriptive statistics, correlations, and the distribution of children in the normal, subclinical, or clinical range were calculated for all outcome variables. Also, the assumption of normality was tested. Secondly, two-tailed independent $t$-tests were performed to check whether the means of the study variables differ significantly between the intervention group and the control group at baseline. Cohen's effect size (ES) $d$ was calculated to determine the size of mean differences (Cohen, 1992). Thirdly, the main study hypotheses were examined by performing separate two-way repeated measures ANCOVA's for each outcome variable (i.e., Time $\times$ Condition). Regarding the first study hypothesis, adaptive ER were controlled for levels of maladaptive ER, while
TABLE 3 | Pre- and post-test reliabilities (Cronbach's $\alpha$ ).

\begin{tabular}{lcccc}
\hline Study variables & $\begin{array}{c}\text { Intervention } \\
\text { group T0 }\end{array}$ & $\begin{array}{c}\text { Intervention } \\
\text { group T1 }\end{array}$ & $\begin{array}{c}\text { Control } \\
\text { group T0 }\end{array}$ & $\begin{array}{c}\text { Control } \\
\text { group T1 }\end{array}$ \\
\hline $\begin{array}{l}\text { 1. Adaptive ER } \\
\text { (FEEL-KJ) }\end{array}$ & 0.91 & 0.95 & 0.94 & 0.96 \\
$\begin{array}{l}\text { 2. Maladaptive ER } \\
\text { (FEEL-KJ) }\end{array}$ & 0.88 & 0.84 & 0.82 & 0.84 \\
$\begin{array}{l}\text { 3. Depressive } \\
\text { symptoms (CDI) }\end{array}$ & 0.78 & 0.86 & 0.80 & 0.89 \\
$\begin{array}{l}\text { 4. EXT problems } \\
\text { (CBCL/TRF) }\end{array}$ & 0.94 & 0.91 & 0.85 & 0.89 \\
$\begin{array}{l}\text { 5. INT problems } \\
\text { (CBCL/TRF) }\end{array}$ & 0.87 & 0.87 & 0.82 & 0.83 \\
\hline
\end{tabular}

ER, emotion regulation; FEEL-KJ, Fragebogen zur Erhebung der Emotionsregulation bei Kindern and Jugendlichen; CDI, children's depression inventory; EXT, externalizing; INT, internalizing; TRF, teacher report form; CBCL, child behavior checklist.

maladaptive ER was controlled for levels of adaptive ER, because adaptive ER and maladaptive ER seem to be correlated (Cracco et al., 2015). Regarding the second study hypothesis, gender differences were controlled for, as it is known from the literature that girls typically experience more IP compared to boys (Crijnen et al., 1997). As EP and IP commonly interfere with each other, EP were controlled for levels of IP, while IP were controlled for levels of EP (Masten et al., 2005). Cohen's effect size $f$ was calculated to determine the interventions' impact magnitude and the level of significance for all analyses was set at $p<0.05$. Fourthly and finally, to determine whether there is a clinically significant change in the intervention group for both the primary and the secondary outcome variables, the Reliable Change Index (RCI) was calculated using the formula from Jacobson and Truax (1991). When the RCI is higher than 1.96, the post-test score is likely to reflect a real change.

\section{RESULTS}

\section{Preliminary Analyses}

Descriptive statistics and correlations for all outcome variables are presented in Tables 4 and 5, respectively (Simons et al., 2016). 
Scores on the primary outcome variables seemed to be positively skewed at T0 and T1 in both the intervention and the control group. Therefore, these were transformed using square root transformation. Furthermore, two-tailed independent $t$-tests showed significant mean differences at baseline between the intervention and the control group for depressive symptoms, $t(160)=p<0.001$, $d=0.63$ and maladaptive ER, $t(146.93)=-3.25=p<0.001$, $d=0.51$. Overall, it can be concluded that the intervention group experiences higher baseline levels of emotional problems compared to the control group.

\section{Primary Outcomes}

Regarding the first confirmatory hypothesis, and more concretely children's adaptive ER, the results showed a significant main effect of time, $F(1,159)=18.04, p<0.001$ and a Time $\times$ Condition interaction $F(1,159)=8.28, p<0.01$, effect size $f=0.23$ (see Figure 2), while no significant effect of condition, $F(1,159)=0.001, p=0.98$ was found. Furthermore, a covariate effect was observed of children's maladaptive ER, $F(1,159)=19.48, p<0.001$. Fifteen children in the intervention group (three in the subclinical and 12 in the normal range) showed significant post-test progression (i.e., RCI > 1.96), compared with seven children in the control group (three in the subclinical and four in the normal range).

Regarding children's maladaptive ER, a significant main effect of time, $F(1,159)=7.12, p<0.01$, condition, $F(1,159)=5.98$, $p<0.05$, and a Time $\times$ Condition interaction, $F(1,159)=5.20$, $p<0.05$, effect size $f=0.18$ (see Figure 2) were found. Furthermore, a covariate effect was observed of children's adaptive ER, $F(1,159)=8.10, p<0.01$. Seventeen children in the intervention group (eight in the clinical, four in the subclinical, and five in the normal range) showed significant post-test progression (i.e., RCI > 1.96), compared with eight children in the control group (one in the clinical, four in the subclinical, and three in the normal range).

Finally, concerning children's depressive symptoms, the results showed a significant effect of condition, $F(1,157)=11.31$, $p<0.001$, while no significant main effect of time, $F(1,157)=1.86$, $p=0.18$, nor of the Time $\times$ Condition interaction, $F(1,157)=2.81$, $p=$ or $<0.10$ (see Figure 2) were found. In the intervention group, subclinical and clinical scores for depressive symptoms were found in $46.0 \%$ of the children at T0. Nine children in the intervention group (four in the clinical and five in the subclinical range) showed significant post-test progression (i.e., RCI > 1.96), compared with two children in the control group (one in the clinical and one in the normal range).

\section{Secondary Outcomes}

Regarding the second exploratory hypothesis, and more specifically regarding children's EP, a significant within-subject effect of time, $F(1,157)=8.81, p<0.01$ was found, while, in contrast, the effect of condition, $F(1,157)=0.27, p=0.61$, and the Time $\times$ Condition interaction, $F(1,158)=0.22, p=0.64$ (see Figure 2) remained insignificant. Furthermore, a covariate effect was observed of children's IP, $F(1,157)=15.98, p<0.001$, while no significant interaction was found between gender and children's EP. Sixteen children in the intervention group (nine in the clinical, five in the subclinical, and two in the normal range) showed significant post-test progression (i.e., RCI > 1.96), compared with 10 children in the control group (one in the clinical, three in the subclinical, and six in the normal range).

Next, regarding children's IP, no significant effects of time, $F(1,157)=0.31, p=0.58$, condition, $F(1,157)=1.78, p=0.18$, nor Time $\times$ Condition interaction, $F(1,158)=1.26, p=0.26$ (see Figure 2) were found. Fourteen children in the intervention group (eight in the clinical, three in the subclinical, and three in the normal range) showed significant post-test progression (i.e., RCI > -1.96), compared with 19 children in the control group (five in the clinical, nine in the subclinical, and five in the normal range).

\section{DISCUSSION}

The current study evaluated the effectiveness of TIME-IN, a school-wide health care policy for promoting school readiness in children with SEN. As pointed out in the Introduction section and based on the arguments of McIntosh et al. (2014),

TABLE 4 | Descriptive statistics.

\begin{tabular}{|c|c|c|c|c|c|c|c|c|}
\hline \multirow{2}{*}{$\begin{array}{l}\text { Conditions } \\
\text { Intervention group }(n=81)\end{array}$} & \multicolumn{4}{|c|}{ TO = Baseline } & \multicolumn{4}{|c|}{ T1 = 9 months later } \\
\hline & $M$ & $S D$ & Min & $\operatorname{Max}$ & $M$ & $S D$ & Min & Max \\
\hline 1. Adaptive ER & 136.01 & 24.96 & 72.0 & 185.0 & 139.35 & 29.68 & 58.0 & 206.0 \\
\hline 2. Maladaptive ER & 78.30 & 18.91 & 40.0 & 130.0 & 74.73 & 15.76 & 36.0 & 118.0 \\
\hline 3. Depressive symptoms & 12.0 & 6.24 & 3.0 & 30.0 & 11.38 & 7.70 & 2.0 & 36.0 \\
\hline 4. EXT & 9.09 & 10.08 & 0.0 & 43.0 & 7.57 & 6.94 & 0.0 & 37.0 \\
\hline 5. INT & 7.73 & 6.82 & 0.0 & 27.0 & 7.69 & 6.38 & 0.0 & 31.0 \\
\hline Control Group ( $n=81$ ) & $M$ & $S D$ & Min & Max & $M$ & $S D$ & Min & Max \\
\hline 1. Adaptive ER & 140.11 & 26.92 & 80.0 & 195.0 & 135.60 & 22.84 & 81.00 & 210.0 \\
\hline 2. Maladaptive ER & 70.81 & 13.86 & 36.0 & 105.0 & 72.57 & 12.18 & 37.11 & 112.0 \\
\hline 3. Depressive symptoms & 8.57 & 5.39 & 1.0 & 27.0 & 9.17 & 6.24 & 0.0 & 34.0 \\
\hline 4. EXT & 6.29 & 5.29 & 0.0 & 26.0 & 5.59 & 5.15 & 0.0 & 32.0 \\
\hline 5. INT & 6.34 & 5.30 & 0.0 & 23.0 & 5.45 & 4.19 & 0.0 & 22.0 \\
\hline
\end{tabular}

Min, minimum; Max, maximum; EXT, externalizing; INT, internalizing; ER, emotion regulation. 
TABLE 5 | Correlations (Pearson's $r$ ).

\begin{tabular}{|c|c|c|c|c|c|c|c|c|c|c|}
\hline Study variables & 1 & 2 & 3 & 4 & 5 & 6 & 7 & 8 & 9 & 10 \\
\hline 1. Adaptive ER TO & - & $0.46^{*}$ & 0.14 & -0.07 & $-0.26^{* *}$ & -0.07 & -0.08 & -0.03 & -0.002 & -0.03 \\
\hline 2. Adaptive ER T1 & & - & $-0.16^{*}$ & 0.01 & -0.14 & $-0.18^{*}$ & -0.06 & -0.001 & 0.002 & -0.06 \\
\hline 3. Maladaptive ER TO & & & - & $0.41^{* * *}$ & $0.39^{* *}$ & $0.39^{* *}$ & -0.10 & 0.04 & 0.09 & 0.03 \\
\hline 4. Maladaptive ER T1 & & & & - & $0.26^{* *}$ & $0.41^{* *}$ & 0.11 & $0.20^{*}$ & 0.0 & -0.07 \\
\hline 5. Depressive symptoms T0 & & & & & - & $0.65^{* *}$ & 0.08 & 0.15 & 0.08 & 0.14 \\
\hline 6. Depressive symptoms T1 & & & & & & - & 0.13 & 0.12 & 0.08 & 0.09 \\
\hline 7. EXT TO & & & & & & & - & $0.64^{* *}$ & $0.37^{* *}$ & $0.34^{* *}$ \\
\hline 8. EXT T1 & & & & & & & & - & 0.15 & $0.40^{* * *}$ \\
\hline 9. INT TO & & & & & & & & & - & $0.63^{* * *}$ \\
\hline 10. INT T1 & & & & & & & & & & - \\
\hline
\end{tabular}

EXT, externalizing; INT, internalizing; ER, emotion regulation. ${ }^{*} p<0.05 ;{ }^{* *} p<0.01$.

TIME-IN aims to extend PBIS and its behavioral interventions by providing emotional learning interventions, which are intended for strengthening children's adaptive ER to the detriment of maladaptive ER, as well as for reducing both EP and IP. More specifically, first, the confirmatory hypotheses were tested whether TIME-IN would be beneficial for improving children's use of adaptive ER strategies, reducing maladaptive ER strategies and lowering depressive symptoms. Secondly, the exploratory hypotheses were tested whether a reduction of EP and IP would occur in the intervention group and whether the same (natural) fluctuations were observable in a control group.

Regarding the primary study outcomes, the results provided modest evidence that TIME-IN had a positive impact on children's emotional learning. More specifically, first, there seemed to be a significant increase of adaptive ER strategies in the intervention group. As these improvements mainly concerned children with normal baseline scores, this finding can be an indication of the importance of implementing primary practices for enhancing all children's emotional competencies (e.g., emotional school and classroom management; see Bradshaw, 2014, p. 99). Secondly, there was also a significant decrease of maladaptive ER strategies. Since this reduction was especially noticeable in children with clinical baseline scores, this result may demonstrate the relevance of implementing secondary and tertiary practices for the most vulnerable children. Thirdly and finally, a trend significant decrease of depressive symptoms $(p<0.10)$ was found, whereby especially children in the subclinical and clinical range showed significant improvements. As the implementation of TIME-IN took place during only one school year, a 9-month intervention period was possibly too short to be fully effective for reducing children's emotional problems (Litschge et al., 2010). Future studies should, therefore, include a longer intervention period, as well as multiple follow-up measurements.

Regarding the secondary study outcomes, first, an effect of time was observed for all children's EP, which seemed to imply a natural decrease of children's behavioral problems over time both in the intervention and control groups. Furthermore, there was no evidence that EP decreased more in the intervention group than in the control group, since time did not seem to interact with condition. Secondly, no significant effects were found regarding children's IP. We assume that as part of the TIME-IN intervention, teachers in the intervention group became more aware of children's emotional problems throughout the school year, which might have contaminated the study findings or that external observers (both parents and teachers) were not ideal informants on children's IP (see, e.g., Theuwis et al., 2013).

As we included only one school for the intervention, the sample included could be too small for strong statistical power and, moreover, this reduced the chance of obtaining reliable and generalizable results (see also Parker, 1990). According to power tables of Cohen (1988, p. 55), however, a total sample size of 28 children per condition should have been sufficient to generate sufficient power (i.e., $1-\beta$ ). Furthermore, combining a small sample size with a relatively high significance level (i.e., 0.05) increases the probability of accepting a false null hypothesis, leaving potential significant effects undetected (i.e., Type II error). Therefore, the optimal level of significance might have to be set higher than 0.05 (e.g., 0.10; Kim and Choi, 2019).

\section{Practical Implications}

The above results entail different implications for promoting school readiness in children with SEN. Firstly, the beneficial impact of TIME-IN on children's ER, as well the observed downward trend regarding children's depressive symptoms, could deliver a rationale for facilitating the overall implementation process of a positive school-wide health care policy on both the schools' meso and micro level, since this contradicts teachers' often persistent conviction that disciplinary practices are the most effective way to address children's behavioral and emotional problems (see Sugai and Horner, 2002; Beets et al., 2008). In addition, as implementation efforts are often accompanied by stress, feelings of incompetence, and resistance to change, these results may convince teachers to participate during sustained implementation efforts (Evers et al., 2002).

Secondly, the results suggest that, besides the implementation of well-known behavioral practices, it is useful for schools to also include emotional learning interventions in special education (McIntosh et al., 2014). More specifically, to enable children to deal with academic stress and related emotions, teachers could be professionalized in screening and training children's emotional competencies such as adaptive ER strategies (Davis and Levine, 2012).

\section{Strengths and Limitations}

Regarding study strengths, first, reliable measures were used, which decreased possible error variance and, as such, increased the study's statistical power. Secondly, the current study had the 


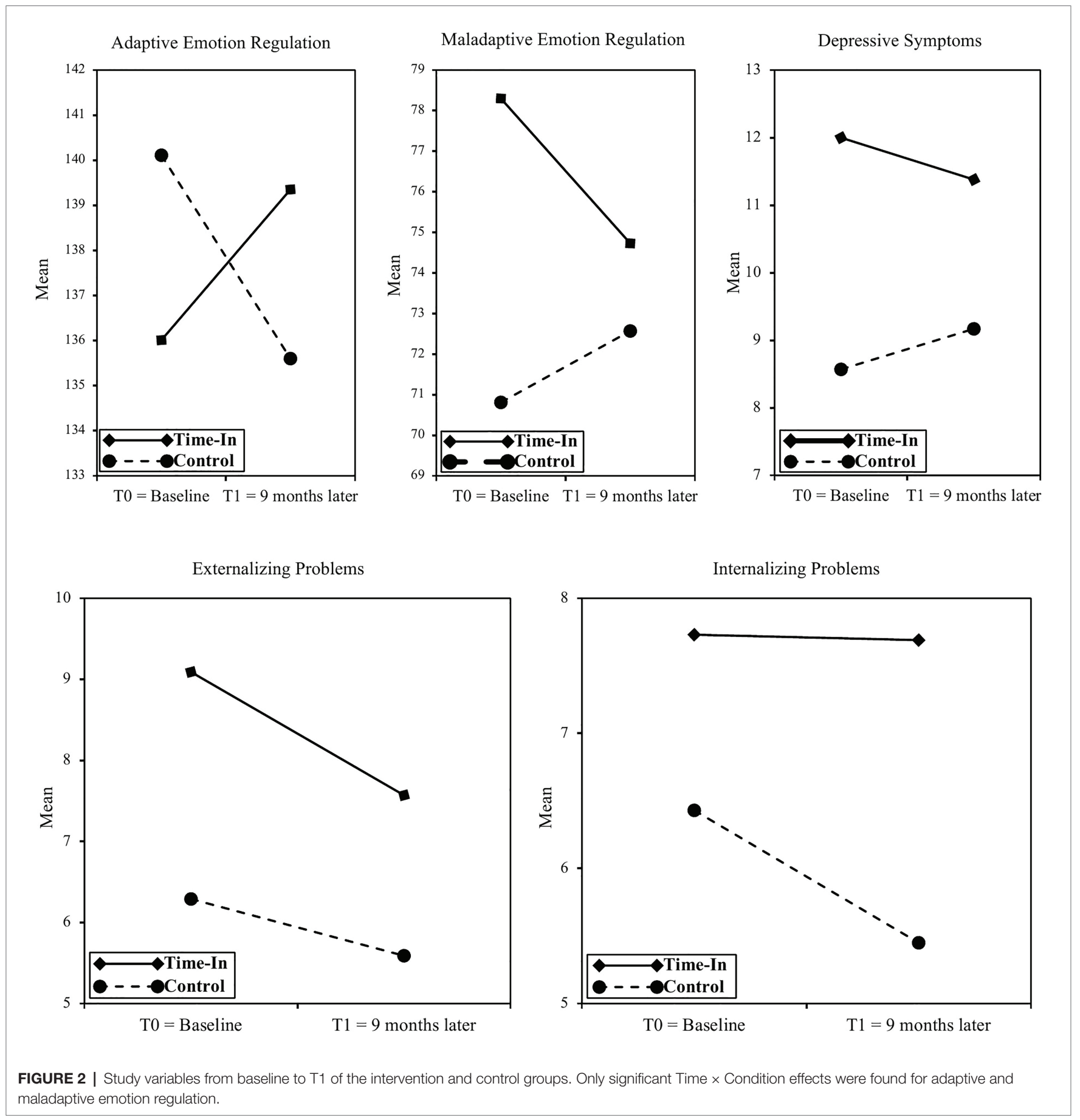

potential to compensate for shortcomings in experimental research as it was conducted in a real-life setting and, as a result, provided "richer" data and increased ecological validity (Schmuckler, 2001). Thirdly, the current study included longitudinal data (i.e., T0 and T1), as well as a matched control group, which may have yielded preliminary signs of causality on the assumed relations between the study variables (Maxwell and Cole, 2007; Veerman and van Yperen, 2007; Simons et al., 2016). This implicated that, within a short time range of 9 months, modest statements could be made about the effects of TIME-IN on children's use of ER strategies. Fourthly and finally, this was one of the first studies investigating a school-wide intervention that aimed to extend PBIS by adding an emotional learning intervention and, moreover, by specifically focusing on improving children's emotional readiness.

Regarding study limitations, first, a design issue occurred. More specifically, there was a lack of randomization, which increased the chance that uncontrolled factors were unevenly distributed over the intervention and the control group. Moreover, both conditions were matched regarding demographical characteristics such as gender and age. However, due to the 
use of opportunity sampling, some baseline scores for the intervention and control groups significantly differed, which suggests that we were not able to take into account maturation effects caused by both child (e.g., SEN status, IQ, and psychosocial problems) or environmental (e.g., SES, educational context, and differences in implementation) factors. Secondly, other threats to internal validity may have occurred, such as testing, regression, differential selection (e.g., bias due to differences between the intervention and control groups related to the composition of normal, subclinical, and clinical scores on the study variables), and selection-maturation interaction (Slack and Draugalis, 2001). All these issues reduced the ability to draw causal conclusions about the effect of TIME-IN on children's school readiness (Simons et al., 2016). To resolve these issues, and to be able to conclude that TIME-IN was efficacious, evidence is required that the presumed outcomes are caused by the intervention and/or its presumed working mechanisms (Veerman and Van Yperen, 2007). In this regard, causal statements typically arise from rigorous evaluations such as a randomized controlled trial (RCT) and/or a single case study. At this moment, we have not yet been able to carry out such research, but, however, we did manage to conduct an additional study to explore change mechanisms (Weymeis et al., 2019a). Thirdly, another study limitation is related to the single use of questionnaires, which may have resulted in shared method variance. This issue could, however, be addressed in the future by including other data sources such as observations, interviews, and children's concrete test results. Fourthly and finally, some issues may have occurred due to the use of teacher- and/or parent reports for our secondary outcome measures. Scores for EP and IP were obtained by different informants in the intervention and control groups (teachers and parents, respectively), which could have led to distorted or tentative results (Simons et al., 2016), as it complicates a reliable comparison. As we were interested in the (experimentally manipulated or naturally) fluctuations between the scores during the 9-month project thereby comparing pre-test vs. post-test scores of the same informant, we believe that the findings on IP and EP were informative to include.

\section{Conclusion}

The current intervention study investigated whether TIME-IN, which extends PBIS by adding an emotional learning intervention, was beneficial for fostering children's school readiness. Overall, the results provided indicative evidence that TIME-IN improved children's ER, which, as a result, may convince schools and teachers to also sustainably implement emotional practices as a classroom management strategy.

\section{Resource Identification Initiative}

This work was retrospectively registered at International Standard Registered Clinical/soCial sTudy Number (ISRCTN) registry ISRCTN54456609 (Weymeis, 2017). ${ }^{3}$ Registered 28 March 2017.

${ }^{3}$ http://www.isrctn.com/ISRCTN54456609?q=\&filters=\&sort=\&offset=3\&totalRes ults $=15635 \&$ page $=1 \&$ pageSize $=100 \&$ searchType $=$ basic-search

\section{AUTHOR'S NOTE}

The authors partially reused T1 data from American Psychological Association (2011) and Weymeis et al. (2019a). The authors furthermore assure that the findings contribute to knowledge/ practice relative to what has already been published in Weymeis et al. (2019a), in accordance with the data reuse guidelines formulated by van Raaij (2018).

\section{DATA AVAILABILITY STATEMENT}

The raw data supporting the conclusions of this article will be made available by the authors, without undue reservation.

\section{ETHICS STATEMENT}

The studies involving human participants were reviewed and approved by Ethical Committee of Ghent University Henri Dunantlaan 2, 9000, Ghent Belgium https://www.ugent.be/pp/ $\mathrm{nl} /$ onderzoek/ec. Written informed consent to participate in this study was provided by the participants' legal guardian/ next of kin.

\section{AUTHOR CONTRIBUTIONS}

HW wrote this report on this TIME-IN clinical trial, assisted with feedback provided by $\mathrm{CB}$ (promotor) and KL (co-promotor). All authors read and approved the final manuscript.

\section{FUNDING}

TIME-IN was implemented as a government funded project (grant FH048-14.10), which supported the involvement of trained psychologists. Furthermore, this work was supported by the Ghent University Special Research Fund under grant number BOF.DC1.2016.0025.01. Ethical requirements were fulfilled.

\section{ACKNOWLEDGMENTS}

We thank "MPI't Craeneveld" for recruiting participants, as well as Elisa Boelens ( $\mathrm{PhD}$ Student at Ghent University) for critically re-reading the manuscript.

\section{SUPPLEMENTARY MATERIAL}

The Supplementary Material for this article can be found online at: https://www.frontiersin.org/articles/10.3389/fpsyg.2021.5798 10/full\#supplementary-material

To ensure complete transparency, a data transparency matrix was submitted as supplementary material (American Psychological Association, 2011). 


\section{REFERENCES}

Achenbach, T. M., Dumenci, L., and Rescorla, L. A. (2002). Ten-year comparisons of problems and competencies for national samples of youth: self, parent, and teacher reports. J. Emot. Behav. Disord. 10, 194-203. doi: 10.1177/106342 66020100040101

Achenbach, T. M., Dumenci, L., and Rescorla, L. A. (2003). DSM-oriented and empirically based approaches to constructing scales from the same item pools. J. Clin. Child Adolesc. Psychol. 32, 328-340. doi: 10.1207/S15374424jccp3203_02

Achenbach, T. M., and Rescorla, L. (2001). Manual for the ASEBA School-Age Forms and Profiles: An Intergrated System of Mult-Informant Assessment. Burlington: VT: University of Vermont, Research Center for Children, Youth, and Families.

Aldao, A., Gee, D. G., De Los Reyes, A., and Seager, I. (2016). Emotion regulation as a transdiagnostic factor in the development of internalizing and externalizing psychopathology: current and future directions. Dev. Psychopathol. 28, 927-946. doi: 10.1017/S0954579416000638

Aldao, A., Nolen-Hoeksema, S., and Schweizer, S. (2010). Emotion-regulation strategies across psychopathology: a meta-analytic review. Clin. Psychol. Rev. 30, 217-237. doi: 10.1016/j.cpr.2009.11.004

American Psychiatric Association (2013). Diagnostic and Statistical Manual of Mental Disorders. 5th Edn. Washington, DC: Author.

American Psychological Association (2011). Data transparency appendix examples. Available at: https://www.apa.org/pubs/journals/apl/data-transparencyappendix-example (Accessed September 29, 2020).

Baker, J. A., Grant, S., and Morlock, L. (2008). The teacher-student relationship as a developmental context for children with internalizing or externalizing behavior problems. Sch. Psychol. Q. 23, 3-15. doi: 10.1037/1045-3830.23.1.3

Bauminger, N., and Kimhi-Kind, I. (2008). Social information processing, security of attachment, and emotion regulation in children with learning disabilities. J. Learn. Disabil. 41, 315-332. doi: 10.1177/0022219408316095

Beets, M., Flay, B., Vuchinich, S., Acock, A., Li, K. K., and Allred, C. (2008). School climate and teachers' beliefs and attitudes associated with implementation of the Positive Action Program: a diffusion of innovations model. Prev. Sci. 9, 264-275. doi: 10.1007/s11121-008-0100-2

Berking, M., and Lukas, C. A. (2015). The Affect Regulation Training (ART): a transdiagnostic approach to the prevention and treatment of mental disorders. Curr. Opin. Psychol. 3, 64-69. doi: 10.1016/ j.copsyc.2015.02.002

Berking, M., and Schwarz, J. (2014). "Affect Regulation Training," in Handbook of Emotion Regulation. ed. J. J. Gross (New York, NY, US: Guilford Press), 529-547.

Blair, C., and Raver, C. C. (2015). School readiness and self-regulation: a developmental psychobiological approach. Annu. Rev. Psychol. 66, 711-731. doi: 10.1146/annurev-psych-010814-015221

Bradshaw, C. (2014). "Positive Behavioral Interventions and Supports," in Proven Programs in Education: Classroom Management and Assessment. ed. R. E. Slavin (Thousand Oaks: Corwin Press), 99-104.

Bradshaw, C. P., Bottiani, J. H., Osher, D., and Sugai, G. (2014). “The Integration of Positive Behavioral Interventions and Supports and Social and Emotional Learning," in Handbook of School Mental Health: Research, Training, Practice, and Policy. eds. M. D. Weist, N. A. Lever, C. P. Bradshaw and J. S. Owens (Boston, MA: Springer, US), 101-118.

Braet, C., Cracco, E., and Theuwis, L. (2013). Questionnaire for Emotion Regulation in Children and Adolescents. Amsterdam: Hogrefe.

Britto, P. R. (2012). School readiness: a conceptual framework. Available at: https://www.unicef.org/education/files/Chil2Child_ConceptualFramework_ FINAL(1).pdf (Accessed June 29, 2020).

Bronfenbrenner, U. (1977). Toward an experimental ecology of humandevelopment. Am. Psychol. 32, 513-531. doi: 10.1037/0003-066X.32.7.513

Cheney, D., Flower, A., and Templeton, T. (2008). Applying response to intervention metrics in the social domain for students at risk of developing emotional or behavioral disorders. J. Spec. Educ. 42, 108-126. doi: 10.1177/00224 66907313349

Cohen, J. (1988). Statistical Power Analysis for the Behavioral Sciences. 2nd Edn. Hillsdale, NJ: Lawrence Erlbaum Associates.

Cohen, J. (1992). A power primer. Psychol. Bull. 112, 155-159. doi: 10.1037/00332909.112.1.155
Cook, C. R., Frye, M., Slemrod, T., Lyon, A. R., Renshaw, T. L., and Zhang, Y. (2015). An integrated approach to universal prevention: independent and combined effects of PBIS and SEL on youths' mental health. Sch. Psychol. Q. 30, 166-183. doi: 10.1037/spq0000102

Cracco, E., Van Durme, K., and Braet, C. (2015). Validation of the FEEL-KJ: an instrument to measure emotion regulation strategies in children and adolescents. PLoS One 10:e137080. doi: 10.1371/journal.pone.0137080

Craighead, W. E., Smucker, M. R., Craighead, L. W., and Ilardi, S. S. (1998). Factor analysis of the Children's Depression Inventory in a community sample. Psychol. Assess. 10, 156-165. doi: 10.1037//1040-3590.10.2.156

Crijnen, A. A. M., Achenbach, T. M., and Verhulst, F. C. (1997). Comparisons of problems reported by parents of children in 12 cultures: total problems, externalizing, and internalizing. J. Am. Acad. Child Adolesc. Psychiatry 36, 1269-1277. doi: 10.1097/00004583-199709000-00020

Davis, E. L., and Levine, L. J. (2012). Emotion regulation strategies that promote learning: reappraisal enhances children's memory for educational information. Child Dev. 84, 361-374. doi: 10.1111/j.1467-8624.2012.01836.x

Dawson, C. A. (2003). A study on the effectiveness of life space crisis intervention for students identified with emotional disturbances. $R C Y$ 11, 223-230.

Dekker, M. C., Koot, H. M., van der Ende, J., and Verhulst, F. C. (2002). Emotional and behavioral problems in children and adolescents with and without intellectual disability. J. Child Psychol. Psychiatry 43, 1087-1098. doi: $10.1111 / 1469-7610.00235$

Evers, W. J. G., Brouwers, A., and Tomic, W. (2002). Burnout and self-efficacy: a study on teachers' beliefs when implementing an innovative educational system in the Netherlands. Br. J. Educ. Psychol. 72, 227-243. doi: 10.1348/ 000709902158865

Farran, D. C., and Shonkoff, J. P. (2010). Developmental disabilities and the concept of school readiness. Early Educ. Dev. 5, 141-151. doi: 10.1207/ s15566935eed0502_5

Flemish Government (2014). Decree concerning measures for pupils with specific educational needs. Available at: https://codex.vlaanderen.be/Portals/Codex/ documenten/1024474.html (Accessed June 29, 2020).

Flemish Government (2017). Statistical Yearbook of Flemish Education. Brussels: Flemish Department of Education, 1-582.

Grob, A., and Smolenski, C. (2005). Fragebogen zur Erhebung der Emotionsregulation bei Kindern und Jugendlichen. Bern: Huber.

Gross, J. J. (1998). Antecedent- and response-focused emotion regulation: divergent consequences for experience, expression, and physiology. J. Pers. Soc. Psychol. 74, 224-237. doi: 10.1037/0022-3514.74.1.224

Horner, R. H., Sugai, G., Smolkowski, K., Eber, L., Nakasato, J., Todd, A. W., et al. (2009). A randomized, wait-list controlled effectiveness trial assessing school-wide positive behavior support in elementary schools. J. Posit. Behav. Interv. 11, 133-144. doi: 10.1177/1098300709332067

Hunter, K. K., Chenier, J. S., and Gresham, F. M. (2013). Evaluation of check in/check out for students with internalizing behavior problems. J. Emot. Behav. Disord. 22, 135-148. doi: 10.1177/1063426613476091

Institute of Medicine (2001). Small Clinical Trials: Issues and Challenges. Washington, DC: The National Academies Press.

Jacobson, N. S., and Truax, P. (1991). Clinical significance: a statistical approach to defining meaningful change in psychotherapy research. J. Consult. Clin. Psychol. 59, 12-19. doi: 10.1037/0022-006X.59.1.12

Kaufman, A. S., Engi Raiford, S., and Coalson, D. L. (2016). Intelligent Testing With the WISC-V. Hoboken, New Jersey: John Wiley and Sons.

Keil, V., and Price, J. M. (2006). Externalizing behavior disorders in child welfare settings: definition, prevalence, and implications for assessment and treatment. Child. Youth Serv. Rev. 28, 761-779. doi: 10.1016/j.childyouth. 2005.08.006

Kim, J. H., and Choi, I. (2019). Choosing the level of significance: a decisiontheoretic approach. Abacus 57, 27-71. doi: 10.1111/abac.12172

Kort, W., Schittekatte, M., Compaan, E. L., Bosmans, M., Bleichrodt, N., Vermeir, G., et al. (2002). WISC-III-NL: Manual Dutch Adaptation. London: The Psychological Corporation.

Kovacs, M. (1992). Children's Depression Inventory. New York: Multi-Health Systems. Lane, K. L., Harris, K. R., Graham, S., Weisenbach, J. L., Brindle, M., and Morphy, P. (2008). The effects of self-regulated strategy development on the writing performance of second-grade students with behavioral and writing difficulties. J. Spec. Educ. 41, 234-253. doi: 10.1177/0022466907310370 
Laros, J. A., Tellegen, P. J., and Wijnberg-Williams, B. J. (1991). Construction and Validation of the SON-R 5-1/2-17, the Snijders-Oomen Non-verbal Intelligence Test. Groningen, The Netherlands: Wolters-Noordhoff.

Litschge, C. M., Vaughn, M. G., and McCrea, C. (2010). The empirical status of treatments for children and youth with conduct problems: an overview of metaanalytic studies. Res. Soc. Work. Pract. 20, 21-35. doi: 10.1177/1049731508331247

Little, R. J. A. (1988). A test of missing completely at random for multivariate data with missing values. J. Am. Stat. Assoc. 83, 1198-1202. doi: 10.1080/ 01621459.1988.10478722

Long, N. J., Wood, M. M., and Fecser, F. A. (2003). Life Space Crisis Intervention. Tielt: Lannoo Campus.

Masten, A. S., Roisman, G. I., Long, J. D., Burt, K. B., Obradovic, J., Riley, J. R., et al. (2005). Developmental cascades: linking academic achievement and externalizing and internalizing symptoms over 20 years. Dev. Psychol. 41, 733-746. doi: 10.1037/0012-1649.41.5.733

Maxwell, S. E., and Cole, D. A. (2007). Bias in cross-sectional analyses of longitudinal mediation. Psychol. Methods 12, 23-44. doi: 10.1037/1082-989X.12.1.23

Mcclure, K. S., Halpern, J., Wolper, P. A., and Donahue, J. (2009). Emotion regulation and intellectual disability. J. Dev. Disabil. 15, 38-44.

McIntosh, K., Ty, S. V., and Miller, L. D. (2014). Effects of school-wide positive behavioral interventions and supports on internalizing problems: current evidence and future directions. J. Posit. Behav. Interv. 16, 209-218. doi: $10.1177 / 1098300713491980$

Morgan, P. L., Farkas, G., Tufis, P. A., and Sperling, R. A. (2008). Are reading and behavior problems risk factors for each other? J. Learn. Disabil. 41, 417-436. doi: $10.1177 / 0022219408321123$

Ollendick, T. H., and King, N. J. (1994). Diagnosis, assessment, and treatment of internalizing problems in children: the role of longitudinal data. J. Consult. Clin. Psychol. 62, 918-927. doi: 10.1037/0022-006x.62.5.918

Organisation for Economic Co-operation and Development (2005). Students with disabilities, learning difficulties and disadvantages: statistics and indicators. Available at: http://www.includ-ed.eu/sites/default/files/documents/sen students_-_statistics_and_indicators_-_oecd.pdf (Accessed June 29, 2020).

Osher, D., Bear, G. G., Sprague, J. R., and Doyle, W. (2010). How can we improve school discipline? Educ. Res. 39, 48-58. doi: 10.3102/0013189X09357618

Parker, R. M. (1990). Power, control, and validity in research. J. Learn. Disabil. 23, 613-620. doi: 10.1177/002221949002301008

Rimm-Kaufman, S. E., and Hulleman, C. S. (2016). "Social and Emotional Learning in Elementary School Settings: Identifying Mechanisms That Matter" in The Handbook of Social and Emotional Learning. eds. J. A. Durlak, C. E. Domitrovich, R. P. Weissberg and T. P. Gullotta (Virginia: The Guilford Press), 1-634

Schmuckler, M. A. (2001). What is ecological validity? A dimensional analysis. Infancy 2, 419-436. doi: 10.1207/S15327078IN0204_02

Simons, D. J., Boot, W. R., Charness, N., Gathercole, S. E., Chabris, C. F., Hambrick, D. Z., et al. (2016). Do "Brain-Training" programs work? Psychol. Sci. Public Interest 17, 103-186. doi: 10.1177/1529100616661983

Slack, M. K., and Draugalis, J. R. (2001). Establishing the internal and external validity of experimental studies. Am. J. Health Syst. Pharm. 58, 2173-2181. doi: 10.1093/ajhp/58.22.2173

Smucker, M. R., Craighead, W. E., Craighead, L. W., and Green, B. J. (1986). Normative and reliability data for the childrens depression inventory. J. Abnorm. Child Psychol. 14, 25-39. doi: 10.1007/BF00917219

Soenen, B., Volckaert, A., D'Oosterlinck, F., and Broekaert, E. (2014). The implementation of life space crisis intervention in residential care and special education for children and adolescents with ebd: an effect study. Psychiatry Q. 85, 267-284. doi: 10.1007/s11126-014-9288-4

Sugai, G., and Horner, R. (2002). The evolution of discipline practices: schoolwide positive behavior supports. Child Family Behav. Ther. 24, 23-50. doi: 10.1300/J019v24n01_03

Tellegen, P. J., Winkel, M., Wijnberg-Williams, B. J., and Laros, J. A. (1998). Snijders-Oomen Nonverbal Intelligence Test. SON-R 21/2-7 Manual and Research Report. Lisse: Swets and Zeitlinger B.V.

Theuwis, L., Braet, C., Roelofs, J., Stark, K., and Vandevivere, E. (2013). Adequate screening of youngsters for depressive characteristics. Psychol. Belg. 53, 51-74. doi: 10.5334/pb-53-2-51

Timbremont, B., and Braet, C. (2002). Children's Depression Inventory: Nederlandstalige Versie ["Children's Depression Inventory: Dutch Version"]. Lisse: Swets \& Zeitlinger.
Van Beveren, M. L., Mezulis, A., Wante, L., and Braet, C. (2016). Joint contributions of negative emotionality, positive emotionality, and effortful control on depressive symptoms in youth. J. Clin. Child Adolesc. Psychol. 48, 131-142. doi: 10.1080/15374416.2016.1233499

van Raaij, E. M. (2018). Déjà lu: on the limits of data reuse across multiple publications. J. Purch. Supply Manag. 24, 183-191. doi: 10.1016/j.pursup. 2018.06.002

Vander Steene, G., and Bos, A. (1997). WPPSI-R. Wechsler Preschool and Primary Scale of Intelligence-Revised. Nederlandstalige Bewerking. Amsterdam: Paerson.

Veerman, J. W., and van Yperen, T. A. (2007). Degrees of freedom and degrees of certainty: a developmental model for the establishment of evidence-based youth care. Eval. Program Plann. 30, 212-221. doi: 10.1016/j.evalprogplan. 2007.01.011

Verhulst, F. C., van der Ende, J., and Koot, H. M. (1996). Manual for the CBCL/4-18. Rotterdam: Afdeling Kinder-en Jeugdpsychiatrie, Sophia. Kinderziekenhuis/Academisch Ziekenhuis Rotterdam, Erasmus Universiteit Rotterdam.

Verhulst, F. C., van der Ende, J., and Koot, H. M. (1997). Dutch Manual for the Teacher's Report Form (TRF). Rotterdam: Afdeling Kinder-en Jeugdpsychiatrie, Sophia. Kinderziekenhuis/Academisch Ziekenhuis Rotterdam, Erasmus Universiteit Rotterdam.

Voeller, K. K. S., and Heilman, K. M. (1988). Attention deficit disorder in children-a neglect syndrome. Neurology 38, 806-808. doi: 10.1212/WNL. 38.5 .806

Volkaert, B., Wante, L., Vervoort, L., and Braet, C. (2018). 'Boost Camp', a universal school-based transdiagnostic prevention program targeting adolescent emotion regulation; evaluating the effectiveness by a clustered RCT: a protocol paper. BMC Public Health 18:904. doi: 10.1186/s12889-018-5754-5

Westwood, P. (2007). Commonsense Methods for Children With Special Educational Needs. 5th Edn. London: Routledge.

Weymeis, H. (2015). Wij Zijn Gedrag: Positief Gedrag in Het Onderwijs. Leuven: Acco.

Weymeis, H. (2017). Promoting positive behaviour and emotional readiness in special education children: effectiveness of a school-wide health care policy TIME-IN. Available at: http://www.isrctn.com/ISRCTN54456609?q= \&filters $=\&$ sort $=\&$ offset $=3$ \&totalResults $=15635$ \&page $=1$ \&pageSize $=100 \&$ search Type=basic-search (Accessed October 16, 2020).

Weymeis, H., Van Leeuwen, K., and Braet, C. (2019a). Adaptive emotion regulation, academic performance and internalising problems in Flemish children with special educational needs: a pilot study. Eur. J. Spec. Needs Educ. 34, 124-135. doi: 10.1080/08856257.2017.1421601

Weymeis, H., Van Leeuwen, K., and Braet, C. (2019b). Extending School-Wide Positive Behavior Support (SWPBS) with emotional support systems: a nonrandomized study testing the effectiveness of a school-wide health care policy TIME-IN in special education. Social Science Protocols 2, 1-16. doi: 10.7565/ssp.2019.2651

Wills, H., Kamps, D., Abbott, M., Bannister, H., and Kaufman, J. (2010) Classroom observations and effects of reading interventions for students at risk for emotional and behavioral disorders. Behav. Disord. 35, 103-119. doi: $10.1177 / 019874291003500203$

Wolff, J. C., and Ollendick, T. H. (2006). The comorbidity of conduct problems and depression in childhood and adolescence. Clin. Child. Fam. Psychol. Rev. 9, 201-220. doi: 10.1007/s10567-006-0011-3

Conflict of Interest: Braet et al. (2013) translated the FEEL-KJ (Grob and Smolenski, 2005) and received an authorship fee for the official version.

The remaining authors declare that the research was conducted in the absence of any commercial or financial relationships that could be construed as a potential conflict of interest.

Copyright () 2021 Weymeis, Van Leeuwen and Braet. This is an open-access article distributed under the terms of the Creative Commons Attribution License (CC BY). The use, distribution or reproduction in other forums is permitted, provided the original author(s) and the copyright owner(s) are credited and that the original publication in this journal is cited, in accordance with accepted academic practice. No use, distribution or reproduction is permitted which does not comply with these terms. 